\title{
Relationship between Work Effectiveness and Readiness to Change among First Line Nurse Managers
}

\author{
Esraa M. Negm 1 , Sohair M. Allam ${ }^{2}$ and Amal R. Gaballah ${ }^{3}$ \\ ${ }^{I}$ BSC in nursing sciences, ${ }^{2}$ Assistant professor of Nursing Administration, ${ }^{3}$ Lecturer of \\ Nursing Administration ,Faculty of Nursing, Menoufia University
}

\begin{abstract}
Background: The importance of readiness to change among first line nurse managers of organization has been recognized as a critical factor in the success of organizational change efforts. These changes within the health care are very important for improving nurse managers' work effectiveness and efficiency. Purpose: This study was carried out to explore the relationship between work effectiveness and readiness to change among first line nurse managers. Design: A descriptive correlational research design was utilized for this study. Setting: Conducted from different departments at Menoufia University Hospital, Teaching Hospital and El Helal Hospital at Shebin-ELkom. Sampling: A Convenience sample of 181 first line nurse managers was included at this study. Instruments: Two instruments were used for data collection. Instrument one: work effectiveness questionnaire (WEQ). Instrument Two: Readiness to change scale. Results: Revealed that the majority of studied first line nurse managers had high level of work effectiveness (94.7\%) , and also the majority of studied nurse managers had a high level of readiness to change (91.4\%). Conclusion: There was a highly statistical significant positive correlation between level of work effectiveness and readiness to change. Recommendation: Strategies and policies should be developed to improve work effectiveness and readiness to change among first line nurse managers.
\end{abstract}

Key Words: Nurse Managers' work effectiveness, readiness to change.

\section{Introduction}

Health care organizations are facing increased with the increasing challenges increasing demand to show positive clinical outcomes and services results by key payers and customers alike. This requires high nursing quality practice which leads to efficient nursing care with reduced length of hospitalization and saving the cost of treatment for patient and hospital (Jones, 2013). In health care system the pace of change has been such as new medical technology, an increasingly demanding customer and patient, shortage of key professionals, globalization and growing financial pressures. Thus, change is the basis for improving and expanding individual, group, and organizational effectiveness, performance and learning (Khammarnia, Ravangard \& Asabi, 2014). 


\section{Nurse Managers}

Work effectiveness is defined as the degree to which objectives and goals are achieved and the extent to which targeted problems are solved (Rosen, 2018). Nursing work effectiveness is primarily related to quality outcome being achieved and is concerned with doing the right things in providing the patient care with low cost and high quality. Quality work performance can be measured by, for instance, the number of errors made by employees (Torres, 2017). Nursing work effectiveness is an indicator of nurse's ability to efficiently execute their nursing duties. (Homa \& Nasreen, 2019). Different factors can influence work effectiveness such as job characteristic, leadership style, compensation justice, and empowerment.

Work effectiveness results from empowering conditions that increase employee's access to conditions that enable them to accomplish their work more effectively. These include access to opportunity, information, support, and resources. Access to opportunities involves work activities that provide challenge, learning, growth and autonomy. Access to information about technical knowledge and organizational goals helps the individual to function more effectively in their role. Employees who receive support in the form of feedback and guidance are also better able to meet role expectations. Access to resources such as equipment, supplies and time to do the work likewise enable role performance. These workplace conditions offer more power to the individual to accomplish their work (Alejandro, Yolanda, Octavio \& Jaume, 2017).

Change is altering the current state of things to give a different position, course or direction and to make a shift from one to another (Yoder-Wise, 2015). Change, whether proactively introduced at the point of change or forced from external sources, affects people. Responses to all or part of the change process by individuals and groups may differ from full acceptance and willing participation to complete rejection or even revolution (Marquis \& Huston, 2015). Additionally, there are three responses to change, namely readiness, commitment and resistance to change. Readiness for change is a cognitive antecedent to behavior of either resistance or support for a change effort, which is reflected in the employee's beliefs, attitudes and intentions regarding the extent to which changes are needed and the organization's ability to successfully complete the intended change (Blackman, O’Flynn \& Ugyel, 2013).

First line nurse managers are responsible for implementing changes in healthcare 


\section{Nurse Managers}

settings, and their insight plays an important role in the change process. Keeping in mind the psychological predispositions of these change recipients, organizations must restore the implementation process so as to create a positive change experience for nurses (Cullen, Tsamenyi, Bernon, \&Gorst, 2013). Managers should create environment that support creativity and openness to motivate nurses to perform beyond standard expectations for performance, and present a vision of the future. Also leaders should provide nurses with new knowledge and skills and give them the opportunity for doing challenging works (Gagnon, Attieh \& Ghandour, 2014).

\section{Significance of the Study}

Health care organizations are facing threatening factors that affect on work effectiveness such as lack of experience, lack of resources, lack of information, lack of skills and lack of managerial support (Wang \& Ashcraft, 2013). Furthermore, there are challenges that may affect on readiness of nurse mangers for change such as increasing cost of health care delivery, the nursing shortage, rapid advancements in technology and information management. First line nurse managers' ability to create and manage meaningful change is an essential skill nowadays. This requires that nurse managers be proactive and creative in guiding change. Therefore, the current study aims to explore work effectiveness among first line nurse managers and its relation to their readiness to change.

\section{Purpose of the study:}

The purpose of this study is to explore work effectiveness level among first line nurse managers and its relation to their readiness to change.

\section{Research questions:}

1. What are the levels of work effectiveness among first line nurse managers?

2. What are the levels of readiness to change among first line nurse mangers?

3. What is the relationship between the first line nurse mangers' level of work effectiveness and their readiness to change?

\section{Methods}

\section{Research Design}

A descriptive correlational research design was used for conducting this study.

\section{Setting}

The study will be carried out at three hospitals in Menoufia Governorate namely, Menoufia University Hospitals which affiliates to Menoufia University, Shebin El-Kom Teaching Hospital which affiliates to general agency of teaching institutes and hospitals and El-Helal 


\section{Nurse Managers}

Insurance Hospital which affiliates to health insurance sector

\section{Sample:-}

The sample consisted of one group of 181first line nurse managers(92 nurse managers from University Hospital,64 from Teaching Hospital and 25 from ElHelal Insurance Hospital)

\section{Sampling technique:}

A convenience sampling technique was used to choose all available first line nurse mangers who fulfill the following criteria:The first line nurse mangers who have at least two year of experience in their position and accept to participate in the study.

\section{Instruments}

\section{Instrument 1: Work Effectiveness Questionnaire (WEQ)}

It was developed by Hanon (2016) and adopted by the investigator to assess work effectiveness level among first line nurse managers. It consisted of two parts:

Part One: It included the participants' demographic information such as age, marital status, qualification, and years of experience.

Part Two: The Work Effectiveness Questionnaire (WEQ) :

It consisted of 50 items aimed to assess the level of work effectiveness among first line nurse managers. It's classified into four domains namely; job characteristic (9 items), leadership style (18 items), compensation justice (11 items) and empowerment (12 items).

The scoring system of each dimension was assessed by using three points Likert Scale ranging from always (3), sometimes (2), never (1). The maximum possible score was 150.The level of work effectiveness was considered low if the score $<60 \%$ (60 - < 90). The level of work effectiveness was considered moderate if the score was between $(60 \%-<75 \%)(90-<113)$. The level of work effectiveness was considered high if the score $\geq 75 \%(113-150)$.

\section{Instrument Two: Readiness to Change scale}

It was developed by El- Beshlawy (2018) and adopted by the investigator to assess readiness to change among first line nurse managers. It consisted of 41 items related to the first line nurse managers' readiness for hospital change. It was classified into four domains namely; appropriateness of change (5 items), managerial support (13 items), change efficacy (12 items) and personal valence (11 items).

The scoring system of each dimension was assessed by using three points Likert Scale ranging from agree (3), neutral (2), disagree (1). Maximum possible score was 123 .The level of readiness to change was considered low if the score $<60 \%$ (41 $<75)$ of total readiness to change score 


\section{Nurse Managers}

moderate if the score was between ( $60 \%$ $<75 \%)(75-<93)$ of the total readiness to change score. The level of readiness to change was considered high $\geq 75 \%$ (93123) of total readiness to change score.

\section{Validity of the instruments}

The study instruments were distributed to a panel of five experts in the field of nursing administration to judge the content and face validity of the instruments. The experts were assistant professors who were affiliated to Faculties of Nursing at Menoufia and Tanta Universities. The instruments were considered valid from the experts' perspectives.

\section{Procedure}

An official letter was sent from the Dean of the faculty of nursing Menoufia University to the directors of Menoufia University Hospital, Shebin El Kom Teaching Hospital and El Helal Insurance Hospital explaining the purpose and methods of data collection. The investigator explained the purpose of the study to every participant. The investigator was available for help to avoid any misinterpretation of questions during data collection. An oral consent was taken from each study participant. Data collection took about three months from the beginning of June 2020 to the end of August 2020.The questionnaires were distributed during nurse's work hours. It took around 15-20 minutes from each study sample to fill in the questionnaire.

\section{Ethical considerations}

Approval was obtained from the Ethics Committee of the Faculty of Nursing, Menoufia University. The privacy and confidentiality of data were maintained and assured by getting participants' consent to participate in the research before data collection. Anonymity of participants was assured.

\section{Statistical analysis}

The collected data were organized, tabulated and statistically analyzed using SPSS (Statistical Package for Social Science)software statistical computer package version 26. For quantitative data, the range, mean and standard deviation were calculated. Comparison was done using Chi-square test $\left(\chi^{2}\right)$. ttest was used to compare between two groups and Anova test (F) test was used for comparison between groups. Qualitative data were presented in the form of frequency distribution tables, number and percentage.

\section{Results}


Relationship between Work Effectiveness and Readiness to Change among First

Line Nurse Managers

Table (1): Distribution of studied nurses according to their social characteristics

\begin{tabular}{|l|l|c|c|}
\hline \multicolumn{2}{|l|}{ Social characteristics } & No. & \% \\
\hline Age / years & $20-<30$ & 60 & 33.1 \\
& $30-<40$ & 85 & 47.0 \\
& $\geq 40$ & 36 & 19.9 \\
\hline Marital status & Married & 150 & 82.9 \\
& Unmarried & 31 & 17.1 \\
\hline Educational level & Bachelor degree & 137 & 75.7 \\
& Master degree & 16 & 8.80 \\
& Doctorate degree & 11 & 6.10 \\
& Others & 17 & 9.40 \\
\hline Hospital of work & Menoufia University Hospital & 92 & 50.8 \\
& Shebin El-Kom Teaching Hospital & 64 & 35.4 \\
& El-Helal Health Insurance Hospital & 25 & 13.8 \\
\hline Years of experience in & $1-<5$ years & 43 & 23.8 \\
nursing & $5-<10$ years & 39 & 21.5 \\
& $\geq 10$ years & 99 & 54.7 \\
\hline Years of experience in & $1-<5$ years & 54 & 29.8 \\
nursing management & $5-<10$ years & 54 & 40.4 \\
\hline & $\geq 10$ years & 29.8 \\
\hline
\end{tabular}

Table (1): Shows Social nursing (75\%). Half of the study characteristics of the studied nurse sample (50\%) is working in university managers. As noticed from the table, hospital. Concerning years of less than half of study sample $(47 \%)$ experience, more than half of the aged between $30-<40$ years old and studied nurse managers (54\%) had $\geq$ most of them were married $(82 \%)$. 10 years of experience in nursing while Furthermore, three quarters of nurse more than one third of them (40\%) had managers had bachelor degree in $(5-<10)$ years of experience in nursing management.

Table (2): Mean and standard deviation of work effectiveness among studied nurse managers 
Relationship between Work Effectiveness and Readiness to Change among First

Line Nurse Managers

\begin{tabular}{|l|c|c|c|c|}
\hline $\begin{array}{l}\text { Work effectiveness } \\
\text { variables }\end{array}$ & Min - Max & Mean & SD & $\begin{array}{c}\text { Mean } \\
\text { percentage }\end{array}$ \\
\hline Job characteristics & $9-27$ & 26.2 & 1.48 & $97 \%$ \\
\hline Leadership style & $18-54$ & 51.9 & 3.31 & $96.1 \%$ \\
\hline Compensation justice & $11-33$ & 31.3 & 2.42 & $94.8 \%$ \\
\hline Empowerment & $12-36$ & 32.6 & 4.41 & $90.5 \%$ \\
\hline Total work effectiveness & $50-150$ & 142.1 & 7.62 & $94.7 \%$ \\
\hline
\end{tabular}

Table (2): shows mean and standard deviation of work among the studied nurse managers. As noticed from table, total work effectiveness and all of its dimensions had high mean scores as compared to the maximum scores. Moreover, the dimension of job characteristics had the highest mean score $(26,2 \pm 1,48)$ with mean percentage $(97 \%)$ (as compared to the maximum score). The dimension of empowerment had the lowest mean score $(32,6 \pm 4,41)$ with mean percentage $(90 \%)$ (as compared to the maximum score).

\section{Total work effectiveness}

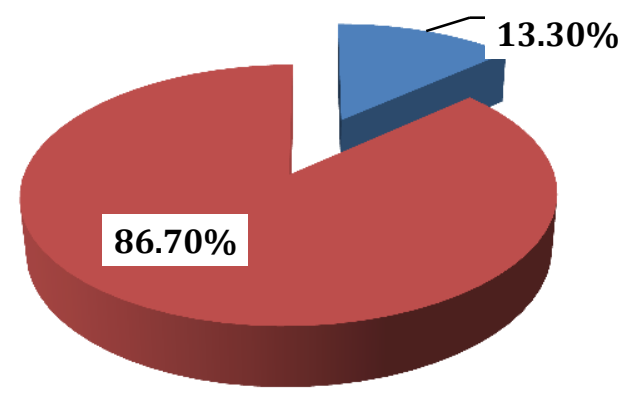

Moderate

High

Figure (1): Percentage distribution of total work effectiveness among the studied nurse managers

Figure (1): Shows percentage effectiveness $(86.7 \%)$ while the distribution of total work effectiveness among the studied nurse managers. As shown in the figure, the majority of nurse managers had high level of work minority of them had moderate level of work effectiveness $(13.3 \%)$. None of them had low level of work effectiveness 
Relationship between Work Effectiveness and Readiness to Change among First

\section{Line Nurse Managers}

Table (3): Mean and standard deviation of readiness to change among the studied nurse managers

\begin{tabular}{|l|l|l|l|l||}
\hline Readiness to change variables & Min - Max & Mean & SD & $\begin{array}{l}\text { Mean } \\
\text { percentage }\end{array}$ \\
\hline Appropriateness to change & $5-15$ & 14.6 & 1.06 & $97.6 \%$ \\
\hline Change efficacy & $12-36$ & 35.1 & 2.09 & $97.5 \%$ \\
\hline Managerial support & $13-65$ & 37.7 & 2.36 & $53.4 \%$ \\
\hline Personal valence with change & $11-33$ & 24.8 & 2.91 & $75.2 \%$ \\
\hline Total readiness to change & $41-123$ & 112.4 & 5.01 & $91.4 \%$ \\
\hline
\end{tabular}

Table (3): shows mean and standard deviation of total readiness among the studied nurse managers. As shown in the table, the total mean score of readiness to change and mean scores of change efficacy was $(97.5 \%)$, and appropriateness to change subscales were high as compared to the maximum scores. On the other hand, managerial support subscales had low mean scores (as compared to the maximum score).

\section{Total readiness to change}

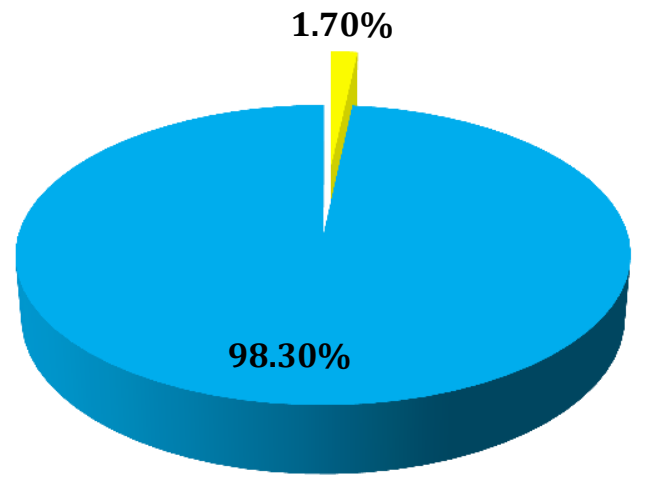

Moderate

$\square$ High

Figure (2): Percentage distribution of total readiness to change among the studied nurse managers $(\mathrm{N}=181)$

Figure (2): shows percentage nurse managers (98.3\%) had high distribution of total readiness to change readiness to change. None of them had among the studied nurse managers. As low level of readiness to change. presented in the figure, the majority of

Table (4): Correlation between work effectiveness and readiness to change among the studied nurse managers $(\mathrm{N}=181)$. 


\begin{tabular}{|l|c|c|}
\hline \multirow{2}{*}{ Studied variables } & \multicolumn{2}{|c|}{ Total work effectiveness } \\
\cline { 2 - 3 } & $\mathbf{R}$ & P value \\
\hline Change efficacy & 0.019 & 0.801 \\
\hline Appropriateness to change & -0.062 & 0.405 \\
\hline Managerial support & 0.058 & 0.438 \\
\hline Personal valence with change & 0.362 & $\mathbf{0 . 0 0 1} * *$ \\
\hline Total readiness to change & 0.233 & $\mathbf{0 . 0 0 1 * *}$ \\
\hline
\end{tabular}

Table (4): shows correlation between work effectiveness and readiness to change among studied nurse managers. As noticed from the table, there was highly statistical significant positive correlation between total work

\section{Discussion}

Organizational effectiveness is usually interpreted as success achieved by an organization in its efforts to achieve predetermined goals. It needs employees able to work well and having high work effectiveness so that the work can run smoothly. The success and failure of an organization to achieve its intended goals depends on the ability of employees to carry out their duties and responsibilities for the tasks assigned to them (Kataria, 2018). Change is an important issue for organizations' survival and it is actually a process in which an organization optimizes performance as it works toward its ideal state. For innovating and improving health care organization, change is required to reach safety, timeliness, effectiveness, effectiveness and readiness to change. While, there was no statistical significant correlation between work effectiveness and change efficacy, appropriateness to change, and managerial support subscales.

efficiency, equity, and patient centeredness (Haroon, Ahmed \& Ghulam, 2019).

Therefore the purpose of this study was to explore the relationship between work effectiveness and readiness to change among first line nurse managers, through: identifying levels of work effectiveness among first line nurse managers, assessing levels of readiness to change among first line nurse managers and finding out the relationship between work effectiveness and readiness to change among first line nurse managers.

The research questions of this study were: "What are the levels of work effectiveness among first line nurse managers?", "What are the levels of readiness to change among first line 


\section{Line Nurse Managers}

nurse mangers?" and "What is the relationship between work effectiveness and readiness to change among first line nurse managers?".

The present study revealed that there was high level of work effectiveness as perceived by the majority of study sample. This answers the first research question "what are the levels of work effectiveness among first line nurse managers?' 'The result of present study was supported by Yong-Sook and Kim (2014) who conducted a study about "Path Analysis of Empowerment and Work Effectiveness among Nurse Managers" and found that work effectiveness had the highest mean score among nurse managers. . In contrast with the findings of present study, Hanon (2016) in a study about perceived level of work effectiveness and readiness to change among oncology nurses reported that most of subjects had moderate and low level of work effectiveness.

Results of the present study revealed that the highest mean score of work effectiveness subscales was for job characteristics subscale. This result was supported by Johari and Yehia (2016) who conducted a study about job characteristics, work involvement and job performance and indicated that the job characteristics were perceived among nurse managers at a high level .On the contrary, Yuxiu (2020) study about job characteristics and job performance among professional nurse managers in the University of Hospital of People's Repuplic of China found that professional nurses perceived that the levels of job characteristics as well as motivation were moderate.

On contrary, the lowest mean score of work effectiveness was related to empowerment. In the same line, Yakob (2018) reported that nurses and physicians reported that mean score of work effectiveness was low in a study about work empowerment as perceived by nurses and physicians working at National Heart Institute. Also Stewart (2020) studied psychological empowerment and structural empowerment among nurse managers concluded that nurse managers who participated in the study had high scores about perceptions of structural empowerment and psychological empowerment.

The present study revealed that there was high level of readiness to change as perceived by the majority of the study sample. This result was supported by Abd-Elkawey (2015) who studied factors affecting nurses' 


\section{Line Nurse Managers}

readiness to change in health care organizations. It was found that the highest percentage $(56 \%)$ of nurse managers reported that they had high readiness to change level. Also, Ashour (2016)found that nurse managers had high readiness to change in a study about factors associated with nurses' readiness to change at Alexanderia Main University Hospital. On the otherhand, the results of Shah (2015) study about determinants of employee readiness for organizational change contradicted with the results of this study as that study revealed a moderate level of readiness to change among head nurses. Moreover, Madsen (2018) study about readiness for organizational change: Do organizational commitment and social relationships in the workplace make a difference, found low level of readiness for organizational change.

This study result revealed that the highest mean score was for appropriateness of change and the lowest mean score was for managerial support. This result was supported by Visage \&Steyn (2015) study about organizational commitment and responses to planned organizational change: An exploratory study as that study found that employees displayed high favorable levels of appropriateness of change. In contrary, Clark (2016) found that participants demonstrated low score toward how legitimate and appropriate the change initiatives were for organization to meet its objective (appropriatness).

The results of the present study showed that managerial support had the lowest mean score. It might be attributed to lack of encouragement from the senior leaders in the form of insufficient resources and information. Besides, lack of desire, support and commitment from senior leaders and top decision makers to implement change in forms of inadequate staff training and development on current issues and trends and lack of reinforcement of new initiatives. In this respect, Mashhady (2021) stated that when employees received timely, informative, and useful information about an organizational change, they presented a more positive evaluation of the change and demonstrated willingness to cooperate with the change agent and low employees' resistance to change.

On the contrary, Visage \& Steyn (2015) found that the employee reflected moderate levels of management support. Also, Clark 


\section{Line Nurse Managers}

(2016) indicated in his study about the development of an integrated measure of readiness for change instrument and its application on aeronautical systems command's contracting directorate that the participants demonstrated moderate level concerning the management support.

The result of the present study showed that there was a high statistical significant positive correlation between work effectiveness and readiness to change.

This result was in the same line with Hanon (2016) who conducted a study about perceived level of work effectiveness and readiness to change and found that there was positive significant correlation between work effectiveness and readiness to change. Besides Maleki, Gohari and Ghorbanion (2019) study about factors affecting readiness to change found that empowerment, leadership, compensation justice and job characteristics could be an antecedent to change acceptance. In addition, trust in management is one mechanism that enables organization members to cope with operational flexibility and constant change.

\section{Conclusion}

Majority of the first line nurse managers in the study settings have high level of work effectiveness and they have high readiness to change. The highest mean score of work effectiveness subscales was for job characteristics subscale and he lowest mean score was for empowerment. The highest mean score of readiness to change was for appropriateness of change and the lowest mean score was for managerial support. The level of work effectiveness is only influenced by marital status and work setting while the readiness to change is affected by age, work setting and years of experience in nursing management. There was highly positive statistical significant correlation between work effectiveness and readiness to change. Moreover, there was highly statistical significant between work effectiveness and personal valence. Hence, improving nurses managers' work effectiveness would foster their readiness to change.

\section{Recommendations}

Based on the findings of this study, the following recommendations are proposed:

$$
\begin{aligned}
& \text { 1- effective and continuous } \\
& \text { training programs should be } \\
& \text { provided for nursing staff based }
\end{aligned}
$$




\section{Line Nurse Managers}

on needs assessment to develop them and so provide high-quality care, increase their work effectiveness, and their readiness to change

2- effective leadership styles should be used according to different situations

3- open communication should be strengthened by conducting schedules for nurses meeting with their managers to reach a high level of work effectiveness

4- a suitable opportunity should be provided for promotion and development for their nurses with a clear path of career, to help to retain effective nurses.

5- an effective compensation program such as bonuses, flexible work hours, and fringe benefits should be provided to increase the commitment, work engagement, and retention of nurses.

6- Strategies for successful change management should be followed by the nurse leaders, with more focus on the expected benefits of the change, and better communication with subordinates.

7- Further researches are required to:

Develop Education program for nurse managers about work effectiveness, and its effect on productivity and quality of care.

\section{References}

Abd-Elkawey,H. (2015). Factors Affecting Nurses' Readiness for Change in Health Care Organizations. International Journal of Nursing Management; Vol 6(2), 155-173. Alejandro, O., Yolanda, B., Octavio, V., \& Jaume, M. (2017). Structural Empowerment and Burnout among Portuguese Nursing Staff: An Explicative Mode. J Nurs Manag; 25:616623.

Ashour, H. (2016). Factors Associated with Nurses' Readiness to Change at Alexanderia Main University Hospital. International Journal of Advances in Nursing Management,Vol 8(3),pp: 237248.

Blackman, D., O’Flynn, J., and Ugyel, L. (2013): A Diagnostic Tool for 


\section{Line Nurse Managers}

Assessing Organizational

Readiness for Complex Change, the Australian and New Zealand Academy of Management conference. An output from the ANZSOG-funded project Diagnosing readiness: Testing organizational capabilities.

Clark,S.(2016). The Development of an Integrated Measure of Readiness for Change Instrument and its Application on ASC/PK. Theses and Dissertations. 4185.

Cullen, J., Tsamenyi, M., Bernon, M., and Gorst, J. (2013): Reverse logistics in the UK retail sector: A Case Study of The Role of Management Accounting in Driving Organizational Change. Management Accounting Research; 24(3): 212-227.

El- Beshlawy, F. (2018): Ability of Decision Making and Its Relation to Readiness to Change among Head nurses. Master Thesis. Faculty of Nursing, Port said University.

Gagnon, M., Attieh, R.\& Ghandour, E. (2014): A Systematic Review of Instruments to Assess Organizational Readiness for Knowledge Translation in Health
Care. PLoS One.; 9(12):e114338. https://doi.org/ $10.1371 /$ journal.pone.0114338.

Hanon, M. (2016): Perception of Work Effectiveness Level and Readiness to change among Oncology Nurses. Master Thesis. Faculty of Nursing. Tanta University.

Haroon, B., Ahmed, H\& Ghulam ,N. (2019): How Does Authentic Leadership Influence Planned Organizational Change? The Role of Employees' Perceptions: Integration of Theory of Planned Behavior and Lewin's Three Step Model. Journal of Change Management, DOI: 10.1080/ 14697017.2017.1299370.

Homa ,K., \& Nasreen, R. (2019): Nursing Efficiency in Patient Care: A Comparative Study in Perception of Staff Nurse and Hospital Management in A Trust Hospital. Journal of Family Medicine and Primary Care. 2019 May; 8(5): 1550-1557

Johari, J., \& Yahya, K. (2016). Job Characteristics, Work Involvement and Job Performance of Public Servants. European Journal of Training and Development, 554-575. 


\section{Line Nurse Managers}

Jones\& R. (2013): Organizational

Theory, and Change, $7^{\text {th }}$ ed.

Chapter 1: Organizations and

Organizational Effectiveness, pp. 23-30.

Kataria, A. (2018). Employee Engagement and Organizational Effectiveness: The Role of Organizational Citizenship Behavior. Journal of Nursing science; 6(1); 100-113

Khammarnia, M., Ravangard, R. \& Asadi, H. (2014): the Relationship of Psychological Empowerment and Readiness for Organizational Changes in Health Workers, Lorestan, IRAN. Journal of Pakistan Medical Association, 64(5):537-541.

Madsem, S. (2018). Readiness for Organizational Change: Do Organizational Commitment and Social Relationships in the Workplace Make a Difference? Human Resource Development Quarterly, vol. 16, no. 2, pp 213233.

Maleki, M., Gohari, M. \& Ghorbanian, A. (2019): Relationship Between Structural Empowering and Nurses' Readiness for Change. Iran Journal of Nursing, 25 (76) $: 10-18$.
Marquis, B. \& Huston, C. (2015): Leadership Roles and Management Functions in Nursing. Theory and Application.8th Edition, chapter 8: planned change; pp.163-180. China: Wolters Kluwer Health, Lippincott Williams \&Wilkins.

Mashhady, A.(2021) Supervisors as Recipients and Implementers of Organizational Change:

Evidence from an Indian Chain Hospital. Journal of Asia Business Studies, 71:109-132.

Rosen, M. (2018). Teamwork in Healthcare; Key Discoveries Enabling Safer, High- Quality Care. The American Psychologist, 73(4),433-450.

Shah, N. (2015). Determinants of Employee Readiness for Organisational Change. Eurasian Journal of Business and Economics, 10(20), 1-16.

Stewart, J.(2020) . Psychological Empowerment and Structural Empowerment among Nurse Practitioners. Journal of American Academy of Nurse Practitioners;22(5) ,27-34.

Torres, M. (2017): "Influence of Work Environment Conditions on The Ability of Critical Care Nurses to 


\section{Line Nurse Managers}

Provide Efficacious Nursing Care in

Puerto Rico". Doctoral Disserations .

1132. https://scholarworks.

umass.edu/dissertations_2/1132

Visagie,C. \& Steyn, C. (2015).

Organisational Commitment and

Responses to Planned

Organisational Change: An

Exploratory Study. Southern

African Business Review 15(3),

91-122.

Wang, L. \& Ashcraft, R. (2013):

Organizational Commitment and Involvement: Explaining the Decision to Give to Associations. Nonprofit and Voluntary Sector Quarterly, 43(25), 615-835.

Yakob,E. (2018). Work Empowerment as Perceived by Nurses and Physicians Working at National Heart Institute. Faculty of Nursing; Ain Shams University. Master thesis. PP; 78-98

Yoder-Wise, P. (2015): Leading and Managing in Nursing, 6th edition, Leading Change; Texas: Elsevier evolve, Lubbock. page 305321 .
Yong- Sook, E\& Kim,Y. (2014): Path Analysis of Empowerment and Work Effectiveness among Staff Nurses. Journal of Asian Nursing.; 8(1) 42-48.

Yuxiu, P. (2020). Job Characteristics and Job Performance among Professional Nurses in the University Hospitals of People's Republic of China. Nat. Sci. Vol. 10(2), 172-182.

Nursing; Ain Shams University. Master thesis. PP; 78-98

Yoder-Wise, P. (2015): Leading and Managing in Nursing, 6th edition, Leading Change; Texas: Elsevier evolve, Lubbock. page 305321.

Yong- Sook, E\& Kim,Y. (2014): Path Analysis of Empowerment and Work Effectiveness among Staff Nurses. Journal of Asian Nursing.; 8(1) 42-48.

Yuxiu, P. (2020). Job Characteristics and Job Performance among Professional Nurses in the University Hospitals of People's Republic of China. Nat. Sci. Vol. 10(2), 172-182. 